\title{
A CPW-Fed Dual -Band Circularly Polarized Antenna for WPT
}

\author{
Fang $\mathrm{Wu}^{1}$, Liguo Sun $^{1+}$ and ZipengXie ${ }^{1}$ \\ ${ }^{1}$ Department of Electronic Engineering and Information Science, University of Science and Technology of \\ China, Hefei, China
}

\begin{abstract}
A novel dual-band circularly polarized (CP) microstrip patch antenna at both $2.45 \mathrm{GHz}$ and 5.8 $\mathrm{GHz}$ is proposed and used for harvesting radio frequency (RF) power in wireless power transmission (WPT). The proposed dual-band circularly polarized microstrip antenna is fed with a coplanar waveguide (CPW) structure. The antenna can operate in both $2.45 \mathrm{GHz}$ and $5.8 \mathrm{GHz}$ withthe return loss $\mathrm{S} 11 \leq-10 \mathrm{~dB}$ and the axial ratio $\mathrm{AR} \leq 3 \mathrm{~dB}$. This antenna can radiate RHCP wave and LHCP wave respectively with the bidirectional performance. The peak value of gain (LHCP) in $2.45 \mathrm{GHz}$ is $3.46 \mathrm{dBi}$, and the peak value of gain (RHCP) in $5.8 \mathrm{GHz}$ is $5.65 \mathrm{dBi}$.
\end{abstract}

Keywords:CPW-feed, circularly polarized, WPT(wireless power transmission), dual-band.

\section{Introduction}

Wireless power transmission (WPT) by microwaveshas been developing for many years since Nikola Tesla did the wireless power transmission experiment for the first timein 1899[1].WPT system includes antenna, rectifying system and matching circuit. The role of receiving antenna is gathering up microwave energy in space and passing to the rectifier circuit. Since both 2.45 and $5.8 \mathrm{GHz}$ are ISM (Industry, Science and Medicine) bands, the WPT applications began to move up to these frequency ranges, especially $5.8 \mathrm{GHz}$ [2]-[4].The rectifying antenna operating at a single frequency of $2.45 \mathrm{GHz}$ or $5.8 \mathrm{GHz}$ has already been widely used. However, the dual-band rectifying antenna is still challenging.

Beside the frequency range, the polarization play an important role in the rectifying antenna. In contrast with linearly polarized (LP), which have higher requirements for the direction of the transmitting antenna [5]-[6], the circularly polarized (CP) antennas have the advantages of mitigated multipath losses and insensitivity toward the equipment's orientation [7]. Since the LP antenna will easily suffer from energy transmission loss if there is a polarization mismatch, CP antenna has been paid more attention. In [8]-[12] some single-band, dual-band and multiband antennas have been proposed for WPT but they are mostly in LP operation.

The antenna mentioned above is mainly dipole and microstrip antenna. Most microstrip antenna, which fed by coaxial probe, have complicated structure and bad for integration. The coplanar waveguide (CPW) feeding structure for planar antenna will greatly benefit the integration since the radiating element and feeding structure of antenna are in the same plane [13].

In this work, a novel CPW-fed dual-band circularly polarized antenna operating at frequency of both $2.45 \mathrm{GHz}$ and $5.8 \mathrm{GHz}$ has been proposed. The new structure not only benefit the integration, but also can realize circular polarization at dual band. The proposed microstrip antenna fed with a CPW structure can operate in both $2.45 \mathrm{GHz}$ and $5.8 \mathrm{GHz}$ with the return loss $\mathrm{S} 11 \leq-10 \mathrm{~dB}$ and the axial ratio $\mathrm{AR} \leq 3 \mathrm{~dB}$, and radiate RHCP wave and LHCP wave respectively. The peak value of gain (LHCP) in $2.45 \mathrm{GHz}$ is $3.46 \mathrm{dBi}$,

+Liguo Sun. Tel.: +0551-3603045; fax: +0551-3603045.

E-mail address:liguos@ustc.edu.cn . 
and the peak value of gain (RHCP) in $5.8 \mathrm{GHz}$ is $5.65 \mathrm{dBi}$. The antenna has been fabricated and the measurement results meets the expectation.

\section{Antenna structure}

Fig.1 (a) illustrates the configuration of the proposed CPW-fed antenna and the fabricated picture is also depicted in Fig. 1(b).

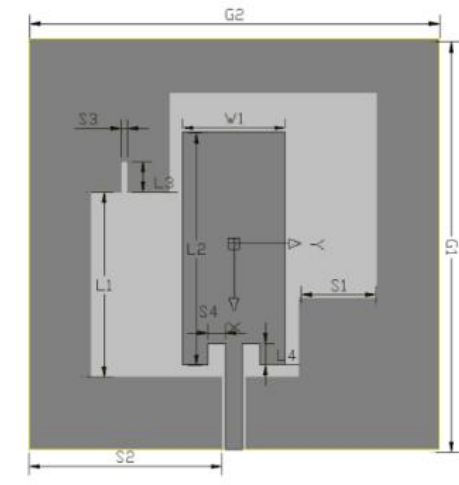

(a) Geometry of the antenna

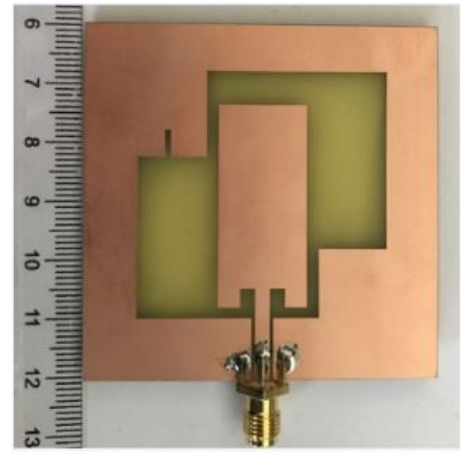

(b) antenna prototype

Fig. 1: Configurations and photograph of the proposed antenna.

It is constructed at the dual frequency of $2.45 \mathrm{GHz}$ and $5.8 \mathrm{GHz}$ on low cost FR4 substrate with dielectric constant $\varepsilon r=4.3$ and substrate thickness of $\mathrm{h}=1.53 \mathrm{~mm}$ and substrate size of $60 \mathrm{mmx} 60 \mathrm{~mm}$. The optimal antenna performance were obtained by using the Ansoft simulation software HFSS.

The characteristic impedance of CPW is adjusted to $50 \mathrm{ohm}$ with the width of the feed $=2.5 \mathrm{~mm}$ and the gap $=0.56 \mathrm{~mm}$. The rectangular patch with a length of $\mathrm{L} 2=34 \mathrm{~mm}$ and width of $\mathrm{W} 1=15 \mathrm{~mm}$ mainly determines the resonance frequency of the antenna. There are two same size slots at the bottom of the patch, the length of the slot is L4=3.1 mm, and width is S4=2.5 mm .By adjusting the size of w1, L2,S4 and L4, the antenna work in dual-band at the same time. Generally speaking, the circular polarized wave are generated by two orthogonal electric field which has equal amplitude and 90 degree phase difference. In order to achieve circular polarization for both frequencies, two metallic rectangular at diagonally opposite corners of the floor and a S3*L3 slot are added.

Table I shows the geometric parameter values optimized by the software.

\begin{tabular}{|l|c|c|c|c|c|c|c|c|}
\hline $\begin{array}{l}\text { Entity } \\
(\mathrm{mm})\end{array}$ & $\begin{array}{c}\text { Antenna Size } \\
(\mathrm{G} 1 * \mathrm{G} 2)\end{array}$ & $\begin{array}{c}\text { Radiation } \\
\text { patch } \\
(\mathrm{W} 1 * \mathrm{~L} 2)\end{array}$ & $\begin{array}{c}\text { Feed } \\
\text { Width }\end{array}$ & Gap & L1 & S1 & S3 & S4 \\
\hline Dimension & $60 * 60$ & $15 * 34$ & 2.5 & 0.56 & 27 & 11.5 & 1 & 2.5 \\
\hline
\end{tabular}

TABLE I. Dimensions of the proposed antenna

\section{Discussion on simulation and measured results}

The size and shape of the rectangle radiation patch have great influence on return loss. Fig. 2(a) reflects the relationship between the return loss and the width $\mathrm{W} 1$ of radiation patch. The $\mathrm{S}$ parameters were measured by using vector network analyzer. As shown in fig. 2(b), the measured and simulated results were compared.

As you can see from the picture, the measured results of return loss is less than $-10 \mathrm{~dB}$ between the frequency range of $2.2 \mathrm{GHz}$ to $3 \mathrm{GHz}$ and $5.6 \mathrm{GHz}$ to $6 \mathrm{GHz}$.Comparedwith the simulation results, the measured curve slightly improved in depth, almost consistent in low frequency band but the resonant point in $5.8 \mathrm{GHz}$ frequency offset slightly to the left. The main cause of the deviation is probably by the error of measurement environment and coaxial connector manual welding. 


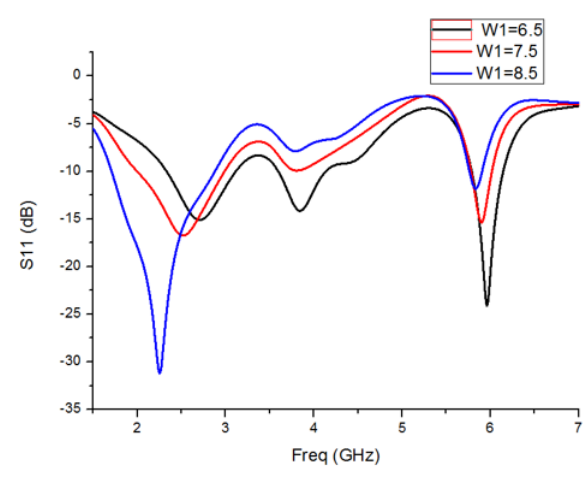

(a)

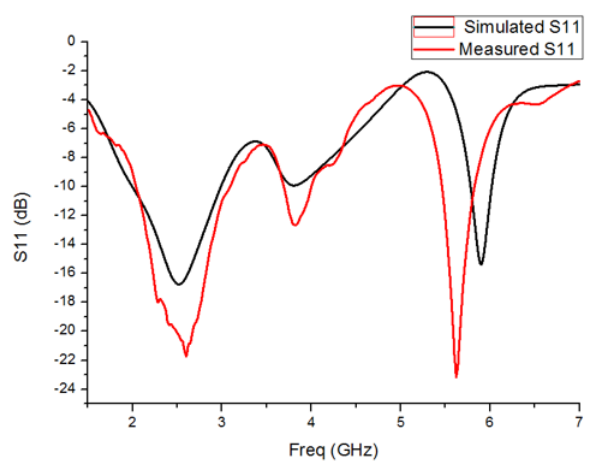

(b)

Fig.2:(a) S11 at different values of W1 (b)Simulated S11 and Measured S11

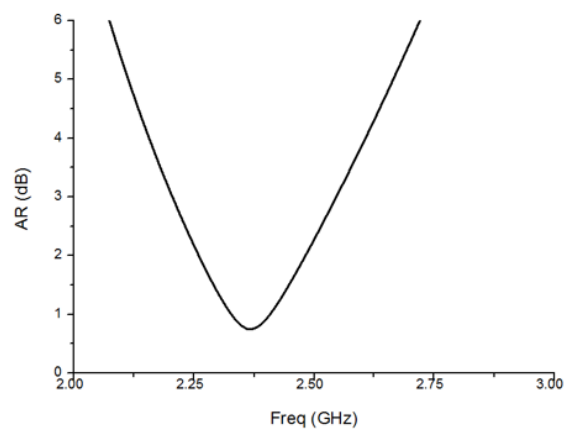

(a)

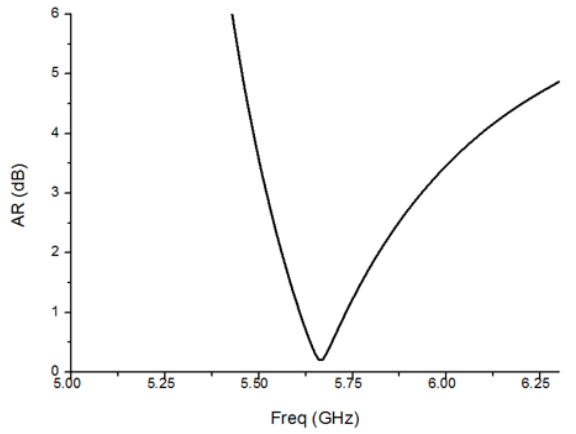

(b)

Fig. 3: (a) Axial Ratio bandwidth at $2.45 \mathrm{GHz}(\mathrm{b})$ Axial Ratio bandwidth at $5.8 \mathrm{GH}$

Figure 3 shows the variation of $\mathrm{AR}$ (in the $+\mathrm{z}$ direction) in dual band. It can be seen that the $\mathrm{AR}$ are 1.5 $\mathrm{dB}$ in $2.45 \mathrm{GHz}$ and $1.8 \mathrm{~dB}$ in $5.8 \mathrm{GHz}$, which meets the requirements of circular polarization on $\mathrm{AR} \leq 3 \mathrm{~dB}$.

The simulated and measured radiation patterns of antenna at center frequency of $2.45 \mathrm{GHz}$ are shown below in fig.4. From the figures, we can see that the measured result is mostly identical to the simulated. The simulated radiation patterns of antenna at center frequency of $5.8 \mathrm{GHz}$ are shown below in fig.5, which has bidirectional radiation pattern in $-z$ direction and $+z$ direction. The peak value of gain (LHCP) in $2.45 \mathrm{GHz}$ is $3.46 \mathrm{dBi}$, and the peak value of gain (RHCP) in $5.8 \mathrm{GHz}$ is $5.65 \mathrm{dBi}$. The $\mathrm{CPW}$ antenna has the performance of bidirectional radiations because the ground plate and the radiating element are in the same plane. This is the reason why the RHCP radiation patterns are similar to LHCP.

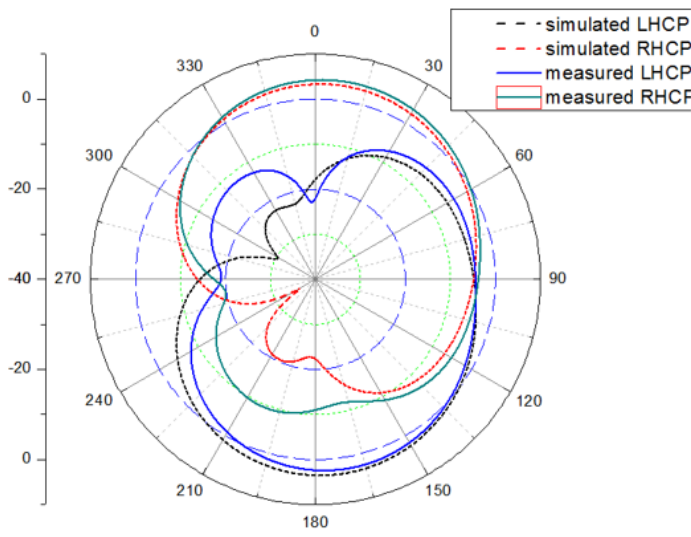

(a)

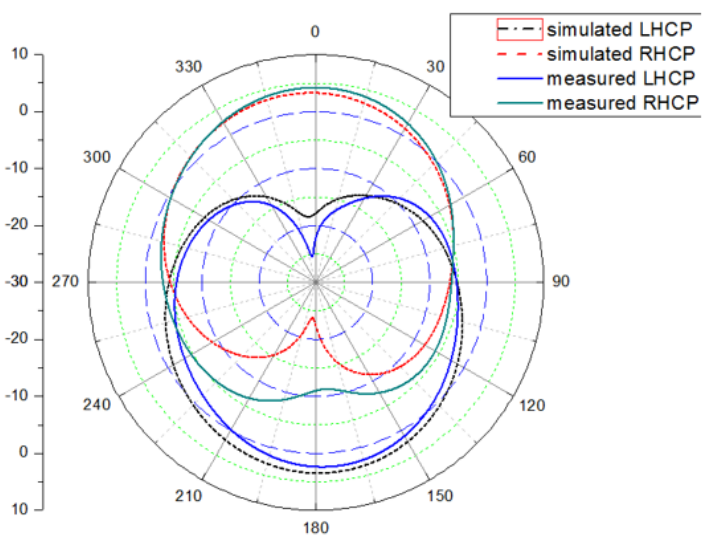

(b)

Fig. 4: Radiation Pattern at 2.45GHz (a) XOZ Plane (b) YOZ plane

There may be two reasons leading to the antenna offset in maximum radiation direction. First of all, the asymmetry of the antenna structure determines the characteristics of the pattern. Secondly, the slot antenna 
generates mutual coupling which is more obvious in high frequency. In a word, the root cause is different working frequency change santenna surface current distribution and then leading to the deviation.

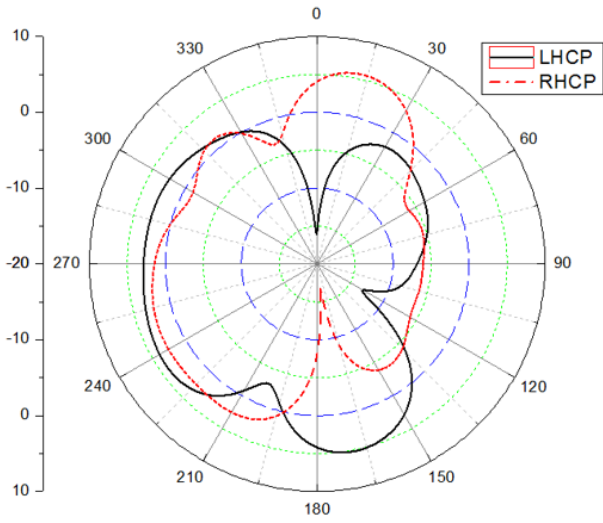

(a)

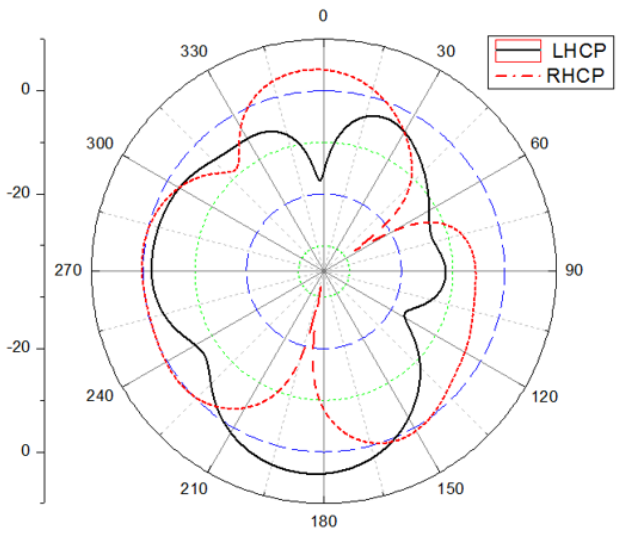

(b)

Fig. 5: Radiation Pattern at 5.8GHz (a) XOZ Plane (b) YOZ plane

\section{Conclusions}

A novel coplanar waveguide (CPW) dual-band circularly polarized antenna has been designed, which not only maintains the characteristics of $\mathrm{CPW}$, but also has the performance of bidirectional radiations. It can meet the requirements of return loss and circular polarization performance in $2.45 \mathrm{GHz}$ and $5.8 \mathrm{GHz}$ by adjusting the parameters of geometrical structure. This antenna is easy to fabricate and simple in structure. The antenna can be used for wireless power transmission.

\section{Acknowledgements}

My grateful to Professor liguo sun and laboratory members for supporting this research work.

\section{References}

[1] W. C. Brown, "The history of power transmission by radio waves," IEEE Trans. Microwave Theory Tech., vol. MTT-32, pp. 1230-1242, Sept. 1984.

[2] Y. H. Suh, K. Chang. A novel dual frequency rectenna for high efficiency wireless power transmission at 2.45 and $5.8 \mathrm{GHz}[\mathrm{C}]$. IEEE Microwave Symposium Digest, 2002 IEEE MTT-S International, 2002, 2: 1297-1300.

[3] J. O. Mc Spadden, L. Fan, K. Chang. Design and experiments of a high-conversion-efficiency 5.8-GHz rectenna [J]. IEEE Transactions on Microwave Theory and Techniques, 1998, 46(12): 2053-2060

[4] B. Strassner, S. Kokel, K. Chang. $5.8 \mathrm{GHz}$ circularly polarized low incident power density rectenna design and array implementation[C]. IEEE Antennas and Propagation Society International Symposium, 2003, 3: 950-953

[5] Y. F. Lin, H. M. Chen, and S. C. Lin, "A new coupling mechanism for circularly polarized annular-ring patch antenna,” IEEE Trans. Antennas Propag. vol. 56, pp. 11--16, Jan. 2008.

[6] K. L. Wong, C. C. Huang, and W. S. Chen, "Printed ring slot antenna for circular polarization," IEEE Trans. Antennas Propag .vol. 50, pp.75-77, Jan. 2002.

[7] G. Augustin and T. A. Denidni, "Coplanar waveguide-fed uniplanar trapezoidal antenna with linear and circular polarization,” IEEE Trans. Antennas Propag. vol. 60, no. 5, pp. 2522-2526, May. 2012.

[8] Y. J. Ren, and K.Chang,5.8-GHz Circularly Polarized Dual-Diode Rectennaand Rectenna Array for Microwave Power Transmission, IEEE Transactions on Microwave Theory and Techniques, Vol. 54, No. 4, pp.1495-1502, 2006

[9] Y. Hiramatsu, T. Yamamoto, K. Fujimori, M. Sanagi, and S. Nogi, "The design of mw-class compact size rectenna using sharp directional antenna," in Eur. Microw. Conf., Sep. 29-Oct. 1, 2009, pp. 1243-1246.

[10] V. Kuhn, C. Lahuec, F. Seguin, and C. Person, "A multi-band stackedRF energy harvester with RF-to-DC efficiency up to 84\%," IEEE Trans.Microw. Theory Techn., vol. 63, no. 5, pp. 1768-1778, May 2015.

[11] J. Heikkinen, P. Salonen, and M. Kivikoski, "Planar rectennas for $2.45 \mathrm{GHz}$ wireless power transfer," in IEEE 
Radio Wireless Conf., 2000, pp. 63-66.

[12] Bhobe A U, Holloway C L, Piket M M. CPW fed wideband hybrid slot antenna [C]. IEEE Antennas and Propagation Society International Symposium. USA: Colorado Univ, 2000: 636-639.

[13] J. S. Row, "Design of square-ringmicrostrip antenna for circular polarisation," Electron Lett., vol. 40, pp. 93--95, Jan. 2004 